\title{
Article \\ Fluorinated Ethylene Propylene Coatings Deposited by a Spray Process: Mechanical Properties, Scratch and Wear Behavior
}

\author{
Najoua Barhoumi ${ }^{1,2} *$ D , Kaouther Khlifi ${ }^{1,2}$, Abderrahim Maazouz ${ }^{3}$ and Khalid Lamnawar ${ }^{3, * \mathbb{D}}$ \\ 1 Laboratoire de Mécanique, Matériaux et Procédés, Ecole Nationale Supérieure d’Ingénieurs de Tunis, \\ Université de Tunis, 5, Avenue Taha Husseïn, Montfleury, Tunis 1008, Tunisia; kaouther.khlifi@ipeiem.utm.tn \\ 2 Institut Préparatoire aux Etudes d'Ingénieurs d'El-Manar, Université d'El-Manar, B.P 244, Tunis 2092, Tunisia \\ 3 CNRS, UMR 5223, Ingénierie des Matériaux Polymères, INSA Lyon, Université de Lyon, \\ F-69621 Villeurbanne, France; abderrahim.maazouz@insa-lyon.fr \\ * Correspondence: najoua.barhoumi@ipeiem.utm.tn (N.B.); khalid.lamnawar@insa-lyon.fr (K.L.)
}

check for updates

Citation: Barhoumi, N.; Khlifi, K.;

Maazouz, A.; Lamnawar, K. Fluorinated Ethylene Propylene Coatings Deposited by a Spray Process: Mechanical Properties, Scratch and Wear Behavior. Polymers 2022, 14, 347. https://doi.org/ $10.3390 /$ polym 14020347

Academic Editor: Carola Esposito Corcione

Received: 26 December 2021

Accepted: 14 January 2022

Published: 17 January 2022

Publisher's Note: MDPI stays neutral with regard to jurisdictional claims in published maps and institutional affiliations.

Copyright: (c) 2022 by the authors. Licensee MDPI, Basel, Switzerland. This article is an open access article distributed under the terms and conditions of the Creative Commons Attribution (CC BY) license (https:/ / creativecommons.org/licenses/by/ $4.0 /)$.

\begin{abstract}
To increase the lifetime of metallic molds and protect their surface from wear, a fluorinated ethylene propylene (FEP) polymer was coated onto a stainless-steel (SS304) substrate, using an air spray process followed by a heat treatment. The microstructural properties of the coating were studied using scanning electron microscopy (SEM) and energy-dispersive X-ray spectroscopy (EDS) as well as X-ray diffraction. The mechanical properties and adhesion behavior were analyzed via a nanoindentation test and progressive scratching. According to the results, the FEP coating had a smooth and dense microstructure. The mechanical properties of the coatings, i.e., the hardness and Young's modulus, were $57 \pm 2.35$ and $1.56 \pm 0.07 \mathrm{GPa}$, respectively. During scratching, successive delamination stages (initiation, expansion, and propagation) were noticed, and the measured critical loads $\mathrm{L}_{\mathrm{C} 1}(3.36 \mathrm{~N}), \mathrm{L}_{\mathrm{C} 2}(6.2 \mathrm{~N})$, and $\mathrm{L}_{\mathrm{C} 3}(7.6 \mathrm{~N})$ indicated a high adhesion of the FEP coating to SS304. The detailed wear behavior and related damage mechanisms of the FEP coating were investigated employing a multi-pass scratch test and SEM in various sliding conditions. It was found that the wear volume increased with an increase in applied load and sliding velocity. Moreover, the FEP coating revealed a low friction coefficient (around 0.13) and a low wear coefficient $\left(3.1 \times 10^{-4} \mathrm{~mm}^{3} \mathrm{~N} \mathrm{~m}^{-1}\right)$. The investigation of the damage mechanisms of the FEP coating showed a viscoelastic plastic deformation related to FEP ductility. Finally, the coating's resistance to corrosion was examined using electrochemical measurements in a $3.5 \mathrm{wt} \% \mathrm{NaCl}$ solution. The coating was found to provide satisfactory corrosion protection to the SS304 substrate, as no corrosion was observed after 60 days of immersion.
\end{abstract}

Keywords: spray process; FEP coating; scratch behavior; friction and wear resistance

\section{Introduction}

Stainless steel is widely use in the fabrication of molds elements using in the chemical and food processing industry, in metal forming and pharmaceutical molds [1-4]. In sliding mechanical systems during service, wear and friction of these metallic components produce several problems and lead to scratches, severe wear, and plastic deformation [5]. Furthermore, in the strongly aggressive media containing chloride anions, stainless steels lack corrosion resistance [6,7]. These failure mechanisms directly involve the molds' surface, creating a serious problem in the manufacturing of casting, and shortens molds' life $[8,9]$. To solve this problem, which causes additional costs for mold reconditioning and reduced productivity, various metallic, ceramic, and polymeric coatings have been proposed. Nickel-based metallic and zirconia-based ceramic protective coatings were deposited on steel diecasting molds [8]. According to Óscar Rodríguez-Alabanda [9], fluoropolymer coatings can be applied as anti-adherent coatings on aluminum-magnesium substrates for food containers. In our previous work [10], polymeric perfluoroalkoxy coatings were used to protect agri-food molds to prevent corrosion and wear. 
Fluorinated polymeric coatings such as polytetrafluoroethylene (PTFE), perfluoroalkoxy (PFA) and fluorinated ethylene propylene (FEP) are the frequently used fluoroplastics [11-13]. These fluorinated polymers are widely applied on molds elements used in the food sector to prevent adherence to substrates, to achieve low chemical reactivity and good corrosion resistance, to facilitate cleaning, to improve unmolding, and to increase the service life of mold elements by protecting their surface from cavity damage through abrasive wear [14]. In this way, chemical stability at high and low temperatures is obtained, and the coating process is simple, short, and leads to low friction coefficients [6,14-16]. These outstanding properties of anti-adherent fluoropolymers result from the fact that $\mathrm{C}-\mathrm{C}$ bonds are strengthened by the incorporation of fluorine atoms into organic materials. In addition, the protective properties of fluoropolymer coatings can be related to the chemical (fluorine and chlorine functional groups) and physical (significant ordering of the polymeric chains) characteristics of the resins [17].

Thanks to its self-lubricating properties, FEP is extensively used in polymer/metal tribological systems working in dry, mixing, and wet environments [18,19]; it also induces high corrosion resistance due to its action as a barrier layer between corrosive species and the metal surface [20]. Fluorinated polymers can be produced by two processes. One of them involves the spray of water-based dispersions of fluoropolymer resins, followed by heat treatment at a temperature between $260{ }^{\circ} \mathrm{C}$ and $360{ }^{\circ} \mathrm{C}$. The thickness of the smooth film produced by this method can reach $1 \mathrm{~mm}$ [21]. The second process involves the electrostatic spraying of polymer powders on a substrate [22]. The first process (spray) is a simple spraying technique with growing scientific interests and industrial applications in the field of industrial molds and components. This method offers corrosion protection and results in increases in mechanical and physical durability and wear resistance.

Recently, efforts have been devoted to exploring the scratch and wear behavior and to enhancing the corrosion and wear resistance of different forms of steel by fluoropolymer coating deposition $[8,9,15,16]$. The coating adhesion of FEP to SS304 is known to be critical, and many studies have been carried out to investigate the scratch behavior and related damage mechanisms of polymeric materials [23] and the adhesion behavior of coatings [24,25]. Xu et al. [23] studied the scratch behavior of alternating multi-layered PMMA/PC materials and found that the delamination process during scratching could be divided into three stages of delamination (initiation, expansion, and propagation).

The protective properties of an FEP coating in saline aqueous solutions, its adhesion using scratch tests, and its wear behavior using multi-pass scratch tests have not yet been investigated. The present work aimed to develop non-stick coatings to protect the SS304 mold substrate and to ameliorate its surface performance. Stainless-steel specimens (SS304) coated with the fluoropolymer FEP were prepared using the spray coating technique. The process parameters of FEP deposit are illustrated. The structure of the FEP coating and its adhesion were studied. Nanoindentation tests were used to investigate the mechanical properties, and the friction and wear properties were explored using multi-pass scratch testing. The aim of this work was to develop FEP-based coatings, sprayed on SS304 steel, and to propose them as a suitable alternative in the manufacture of wear-resistant, anti-adherent, and corrosion-resistive molds.

\section{Materials and Methods}

\subsection{Material}

A stainless steel (SS304) sheet with a chemical composition according to Table 1 was machined to rectangular specimens with dimensions of $100 \times 80 \times 2\left(\mathrm{~mm}^{3}\right)$. The FEP resin, supplied by Whitford (England) as an aqueous solution with a purity of $99.9 \%$, was used to coat the steel substrates. The coating deposition was carried out by RIET industry (Zaghouan-TUNISIa). 
Table 1. Chemical composition of SS304.

\begin{tabular}{lcccccccccccc}
\hline Element & Fe & C & Si & Mn & P & S & N & Cr & Mo & Ni & Cu & Co \\
\hline $\mathrm{W}_{\mathrm{t}}(\%)$ & 70.594 & 0.049 & 0.42 & 1.9 & 0.024 & 0.025 & 0.078 & 18.1 & 0.35 & 8.06 & 0.35 & 0.05 \\
\hline
\end{tabular}

\subsection{Coating Deposition}

Before coating deposition, the steel substrate was cleaned with acetone and polished with a series of silicon carbide sandpapers. Subsequently, it was roughened by sandblasting to a surface finish $\mathrm{Ra} \approx 3 \mu \mathrm{m}$. Then, it was dried at $60^{\circ} \mathrm{C}$ for $24 \mathrm{~h}$. Figure 1 details the deposition of the FEP solution onto the substrate surface using the air spray process. An FEP coating was obtained by repeating the spraying-drying process twice. The spray conditions were maintained at a liquid flow rate of $2.5 \mathrm{~mL} \mathrm{~min}^{-1}$, an air pressure of 3 bars, and a nozzle-to-substrate distance of $8 \mathrm{~cm}$.

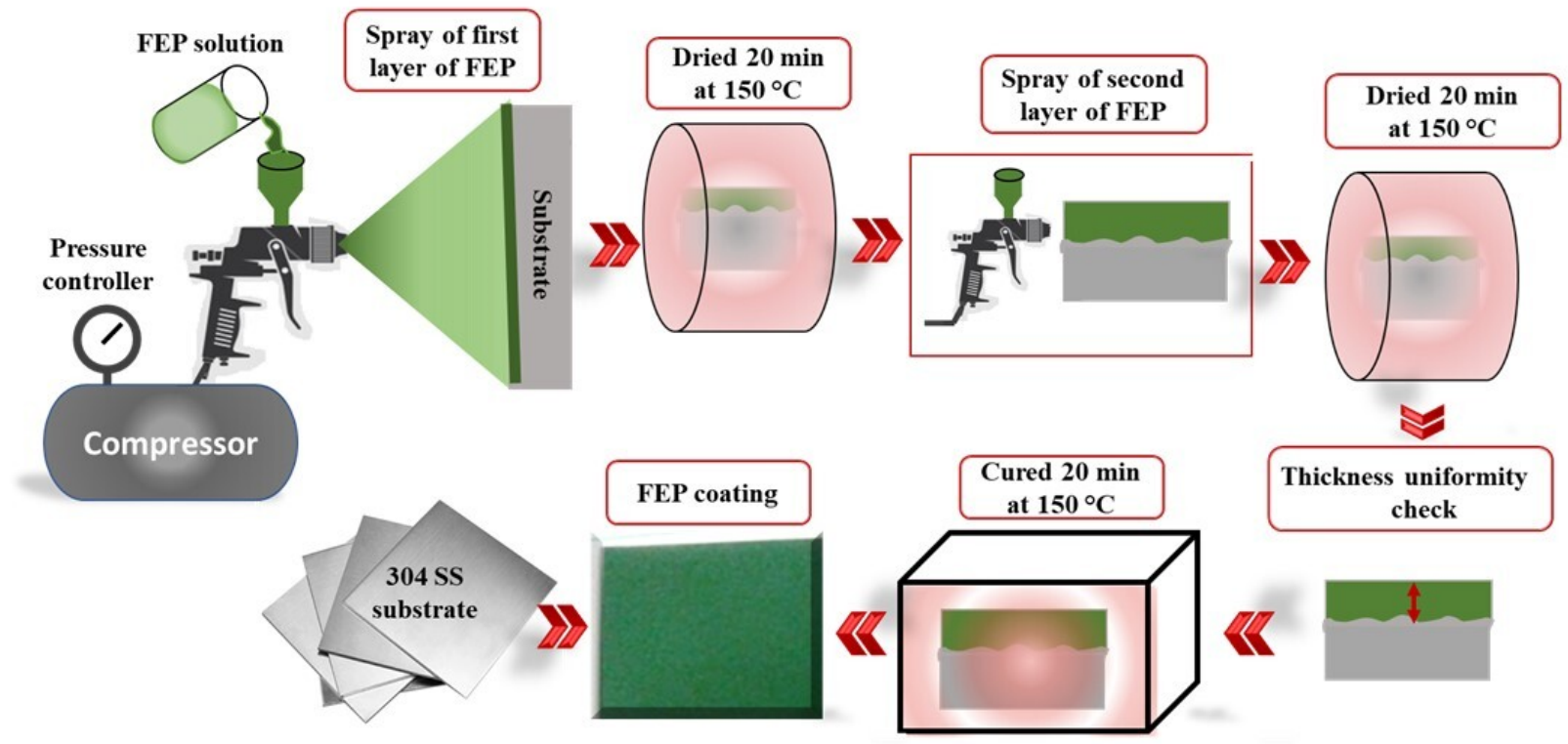

Figure 1. Processing cycle of FEP spraying on stainless steel.

The FEP solution was first applied by air gun spraying to the substrate, after which the materials were dried at $150{ }^{\circ} \mathrm{C}$ for $20 \mathrm{~min}$, as shown in Figure 1. This was followed by a second round of the specimens being spray-coated with FEP and dried in an oven at $150{ }^{\circ} \mathrm{C}$ for $20 \mathrm{~min}$. Subsequently, they were cured at $380^{\circ} \mathrm{C}$ for $25 \mathrm{~min}$ for the coating to melt and spread over the substrate. Finally, they were cooled to ambient temperature. The thickness of the coatings was measured with a standard gauge (Ecotest plus device) and was found to be in the range of $44 \pm 4 \mu \mathrm{m}$. Mechanical and wear characterization tests were conducted and repeated five times on the deposited FEP coatings.

\subsection{Structural Characterization}

The film composition and the microstructure of FEP coatings were evaluated using Scanning Electron Microscopy (SEM-JEOL JSM 6460LV -Suisse) in combination with energydispersive X-ray spectroscopy (EDS) for the identification of the chemical composition. $\mathrm{X}$-ray spectra were obtained at a primary beam energy equal to $20 \mathrm{keV}$ with an acquisition time of $120 \mathrm{~s}$. The study of the phase composition of the samples was performed using X-ray diffraction (Bruker D8 Advance), and X-ray patterns were gathered from $2 \theta=10^{\circ}$ to $70^{\circ}$.

\subsection{Nanoindentation Testing}

The mechanical properties of the FEP coatings (hardness and Young's modulus) were studied using the nanoindentation technique developed by CSM Instruments (Anton Paar, 
Graz, Austria). Tests were conducted with a nanoindenter equipped with a diamond Berkovich tip with a nominal angle equal to $65.3^{\circ}$ and a nominal radius curvature of $20 \mathrm{~nm}$. The maximum applied load was $10 \mathrm{mN}$, and the penetration depth was set to a value lower than $1 / 10$ th of the coating thickness to provide the real film properties and avoid the substrate effect [26]. A minimum of 15 measurements were carried out for each coating to ensure the reproducibility and repeatability of the results. The analysis of load-displacement graphs with the Oliver and Pharr method [27] allowed an estimation of the mechanical properties (Young's modulus, hardness of the film).

\subsection{Scratch Testing}

Film adhesion was investigated with a micro-scratch tester from CSM Instruments (Anton Paar). The indenter was equipped with a Rockwell diamond tip with a radius of $200 \mu \mathrm{m}$. The test was performed in progressive mode in a loading range between 0.3 and $25 \mathrm{~N}$ along $3 \mathrm{~mm}$ of the scratch length, to study the adhesion behavior and to determine the critical loads of the film. The scratch speed was $10 \mathrm{~mm} \mathrm{~min}^{-1}$.

The tests were carried out in three consecutive steps: a pre-scan at $300 \mathrm{mN}$ to determine the initial profile of the samples, a progressive scan from 0 to $25 \mathrm{~N}$ during which the penetration depth $\left(\mathrm{P}_{\mathrm{d}}\right)$ was recorded in real time, and a post-scan at $100 \mathrm{mN}$. SEM was used to study the shape of the residual deformations after the scratch tests. Finally, the indenter conducted a post-scan at a constant load of $300 \mathrm{mN}$ and measured the residual depth $(\mathrm{Rd})$ of the scratch. After the test, the scratch morphology was examined by SEM. At least three progressive load scratch tests were carried out for each sample.

\subsection{Tribological Characterization}

Tribological tests were performed at a constant normal load using a multi-pass scratch test (CSM Instruments, Anton Paar, Graz, Austria) under a unidirectional loading over a sliding distance (d) of $3 \mathrm{~mm}$. Each test was carried out at a temperature of $22{ }^{\circ} \mathrm{C}$ and a relative humidity of $46 \%$. The applied load, $\mathrm{F}_{\mathrm{n}}(1$ and $3 \mathrm{~N})$, the number of passes (100 for each load condition), and the sliding speed (V) were controlled and fixed during the wear testing. Then, wear tracks were examined by SEM.

For each test, the wear volume (V) was calculated by measuring the surface profile on the wear track, and the dissipated energy was determined with the following Formula (1) [28].

$$
E=\sum \overrightarrow{F_{t}} \cdot \vec{d}=v \cdot t \sum F_{t}
$$

where $F_{t}$ is the tangential load $(\mathrm{N}), d$ denotes the sliding distance $(\mathrm{m}), v$ is the sliding velocity $(\mathrm{m} / \mathrm{s})$, and $t$ is the experiment duration (s). The wear coefficient is defined as the slope of the curve of the wear volume $(\mathrm{V})$ vs. energy $(E)$. A low coefficient wear corresponds to a high wear resistance.

\subsection{Corrosion Test}

The electrochemical experiments were performed in a conventional three-electrode system in which a saturated calomel electrode (SCE) was used as a reference electrode, a platinum sheet was taken as a counter electrode, and specimens (SS304 and FEP/SS304) with a $1.0 \mathrm{~cm}^{2}$ area were exposed as the working electrode. Electrochemical measurements were carried out in $3.5 \% \mathrm{NaCl}$ solution after a stabilization period of $1 \mathrm{~h}$ to attain stable $\mathrm{E}_{\text {corr }}$ values. The experiments were also conducted on the coated samples after continuous immersion in $3.5 \mathrm{wt} \% \mathrm{NaCl}$ solution for 60 days.

Polarization studies were performed in an Electrochemical VoltaLab PGZ 301 (Lyon, France). Both cathodic and anodic polarization curves were recorded, and Tafel polarization curves were obtained by varying the electrode potential value from -0.6 to $0.4 \mathrm{~V}$ at a scan rate of $10 \mathrm{mV} \mathrm{S}^{-1}$. The corrosion parameters included the corrosion potential $\left(\mathrm{E}_{\mathrm{corr}}\right)$ and 
the corrosion current $\left(\mathrm{I}_{\mathrm{corr}}\right)$, and the inhibition efficiency (I.E) was calculated by using Equation (2):

$$
\mathrm{I} . \mathrm{E}=\left(1-\frac{\text { icorr }_{\text {coating }}}{\text { icorrsS304 }_{\text {SS }}}\right) \times 100
$$

\section{Results and Discussion}

\subsection{Microstructural Properties}

The microstructure of the sprayed coatings is presented in Figure 2. From the top-view SEM micrographs (Figure 2a), it can be observed that the FEP coatings had a dense, poreless, and homogeneous structure. According to the EDS analysis (Figure 2b), the elementary composition of the prepared FEP coating consisted of $C$ and F, suggesting that the coating was extraordinarily pure.
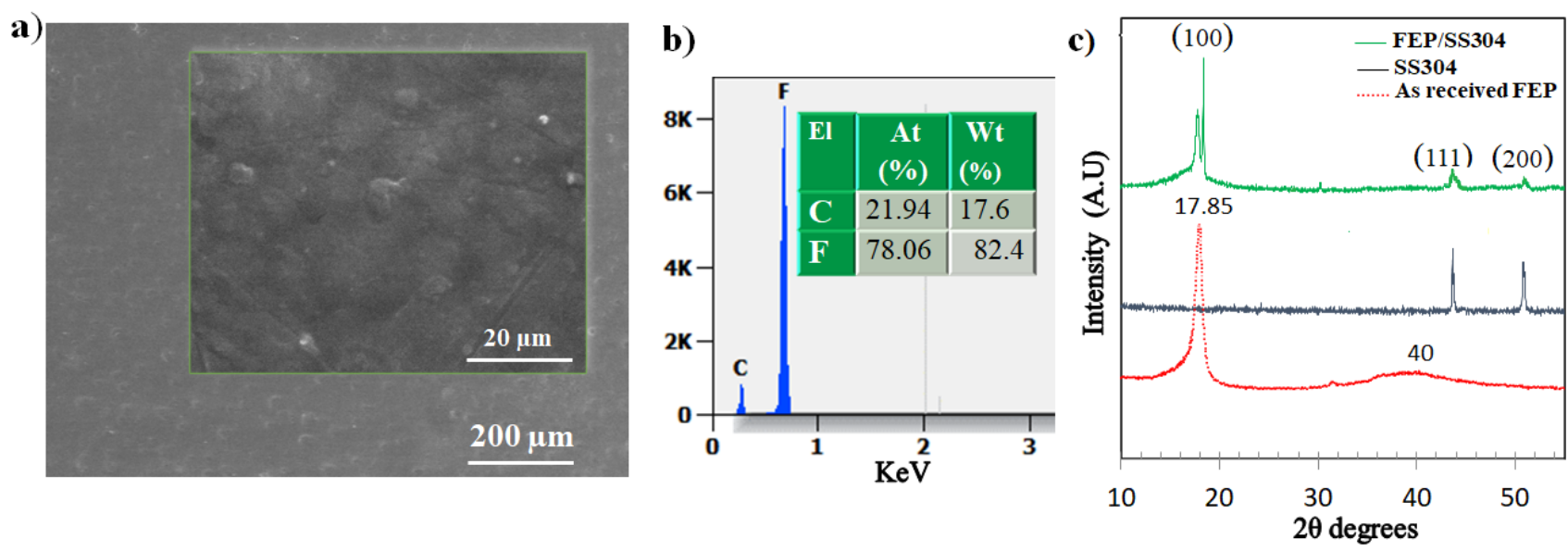

Figure 2. (a) SEM analysis of the FEP coatings, (b) a typical EDS spectrum, and (c) XRD pattern of the coatings.

XRD spectrums of as-received FEP, FEP coating, and SS304 substrate are shown in Figure 2c. The XRD diffractogram of as-received FEP resin was characterized by a sharp peak with the highest intensity and a broad peak. In general, a polymer with a crystalline region presents sharp X-ray diffraction peaks, whereas the X-ray diffraction peaks are broad for an amorphous polymer [29]. The FEP resin had a semicrystalline structure which resulted in a definite crystalline peak at a value of $2 \theta=17.85^{\circ}$ and a spread amorphous peak at $2 \theta=40^{\circ}$. Similar results were obtained by Tcherdyntsev et al. [30]. The XRD spectrum of the FEP coating showed that the crystalline peak in the $2 \theta$ range of $17-19^{\circ}$ corresponded to the (100) plane of two-dimensional hexagonal packing [31]. According to Wesley et al. [31], the peak with the highest intensity $\left(2 \theta=17.85^{\circ}\right)$ is generally associated with the crystalline phase, in which the incident X-ray is diffracted by the plane (100) of the pseudohexagonal lattice structure.

\subsection{Mechanical Properties}

To investigate the mechanical behavior of the FEP coatings, they were subjected to nanoindentation measurements. During the indentation test, the penetration depth increased as a function of the applied load, and a plastic deformation occurred until the maximum load corresponded to the maximum loading. A typical load-depth curve is plotted in Figure 3, and as can be seen, the FEP coatings demonstrated an elasto-plastic behavior. The analysis of the load-depth curves using the Oliver-Pharr method [27] makes it possible to estimate mechanical properties, i.e., hardness, $\mathrm{H}$, and Young's modulus, E, of films. The elastic modulus and the hardness of the coatings are presented in Figure $3 \mathrm{~b}$ and were found to be $57 \pm 2.35 \mathrm{MPa}$ and $1.56 \pm 0.07 \mathrm{GPa}$, respectively. 

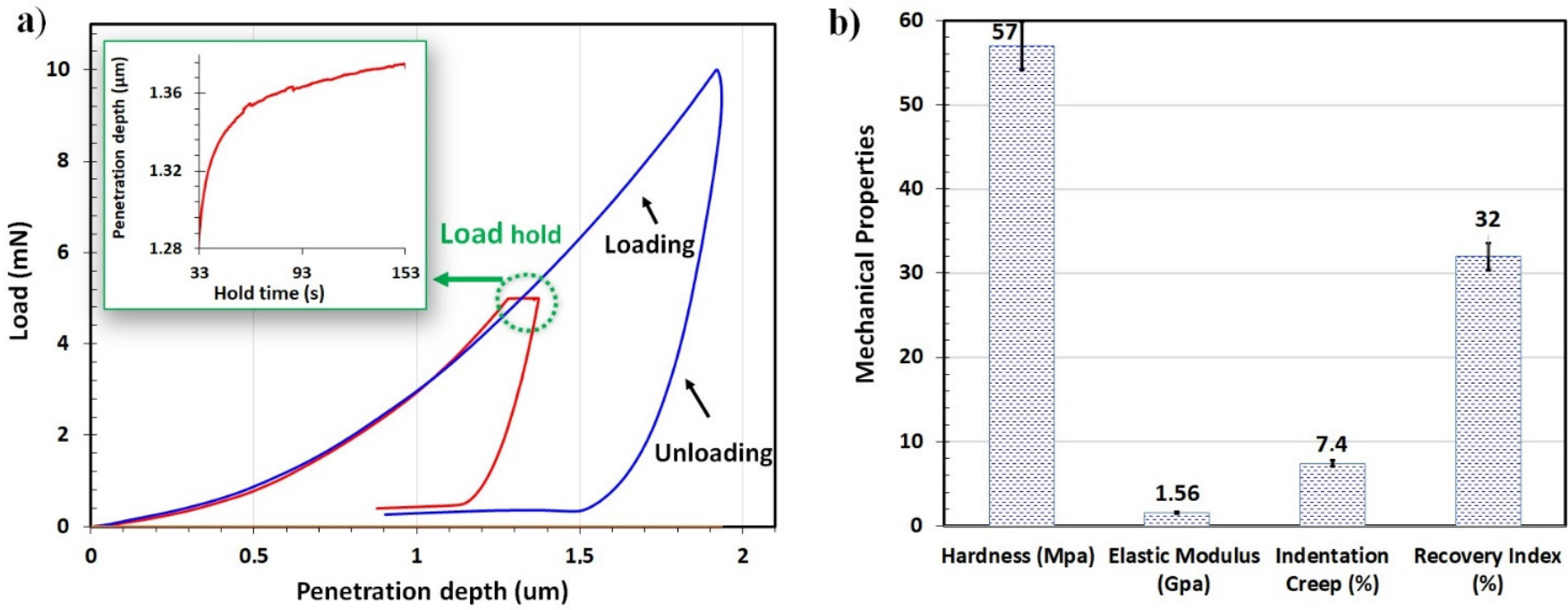

Figure 3. (a) Load-depth curves for FEP coatings with 5 and $10 \mathrm{~m} \mathrm{~N}$ maximum load and (b) measured values from nanoindentation tests on FEP coatings.

The indentation loading/unloading curve of the polymers appeared to be dependent on the holding time, as shown in the inset of Figure 3a. At the applied load of $10 \mathrm{mN}$, the penetration dept increased with time, indicating creep of FEP. The recovery index and indentation creep were derived from the standard nanoindentation measurements (Figure $3 b$ ). The film recovery index $\mathrm{W}_{\mathrm{e}} / \mathrm{W}_{\mathrm{t}}$ implied an elastic recovery during unloading and a significant plastic deformation $(70 \%)$ during loading.

\subsection{Scratch Behavior}

Figure 4a-e shows the results of conventional scratch tests on the FEP coatings. As the normal load increased, the width of the scratch became larger, and partial delamination of the FEP coating occurred at the end of the groove. The scratch progression was accompanied by successive degradations defined by three different critical loads $\left(\mathrm{L}_{\mathrm{c} 1}, \mathrm{~L}_{\mathrm{c} 2}, \mathrm{~L}_{\mathrm{c} 3}\right)$ [25]. These critical loads were determined by combining SEM observations of scratch tracks and the measurements of normal and tangential loads, as well as the penetration and residual depths during the scratch test.

The first critical load $\mathrm{L}_{\mathrm{c} 1}$ corresponding to the appearance of the first crack along the scratch pattern was localized at the edge, thus indicating cohesive failure. The second critical load $\mathrm{L}_{\mathrm{c} 2}$ was the applied normal load at which the extent of fracture events increased both at the bottom and at the edge of the scratch pattern, thereby leading to the observed repeated tensile cracking (adhesive failure). The third critical load $\mathrm{L}_{\mathrm{c} 3}$ was the applied normal load at which the coating exhibited a partial spalling.

Along the scratch path, the photos (Figure 4a-d) revealed that the scratch formed on the FEP coating could be divided into three stages. Stage I (until $\mathrm{L}_{\mathrm{c} 1}=3.36 \mathrm{~N}$ ), termed as smooth sliding, was the initial deformation stage of the FEP coating. Stage II (between $\mathrm{L}_{\mathrm{c} 1}=3.36 \mathrm{~N}$ and $\mathrm{L}_{\mathrm{c} 2}=6.2 \mathrm{~N}$ ) was the transition region between smooth sliding and material removal featured by periodic micro-cracks. Stage III (from $\mathrm{L}_{\mathrm{c} 2}=6.2 \mathrm{~N}$ ) was defined as the material removal region where damage occurred and finally led to mass loss of FEP at $\mathrm{L}_{\mathrm{c} 3}=7.6 \mathrm{~N}$.

Figure $4 \mathrm{e}$ depicts the trends of the tangential force, penetration, and residual depth vs. normal force during the scratch test. The results were superimposed with the related SEM images of the residual scratch tracks of the investigated coatings. A purely elastic deformation took place at low applied scratch loads, and no scratch marks were detected along the starting segment of the scratch track, as shown in Figure 4a,e. By augmenting the normal load, as demonstrated in Figure 4e, a sudden slope change in the friction load and depth curves related to a first cracking phenomena was detected. This cohesive failure at $\mathrm{L}_{\mathrm{c} 1}$ was confirmed by SEM images (Figure $4 \mathrm{~b}$ ). When the applied load increased, the 
track demonstrated a propagation of micro-cracks, indicating adhesive failure at $\mathrm{L}_{\mathrm{c} 2}$. At the highest critical load $\mathrm{L}_{\mathrm{c} 3}$, a partial delamination was observed, thus indicating that the FEP coating bestowed good scratch resistance on the stainless-steel substrate.
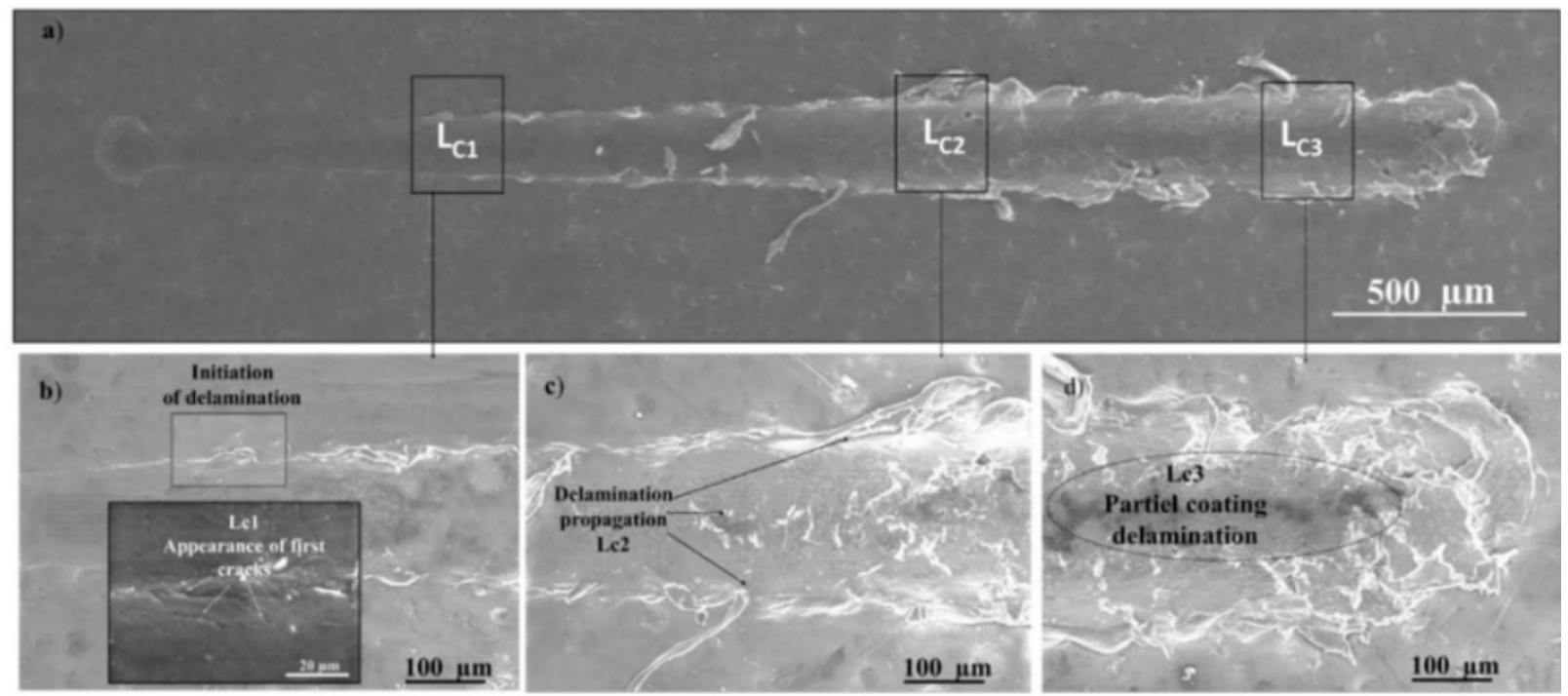

e)

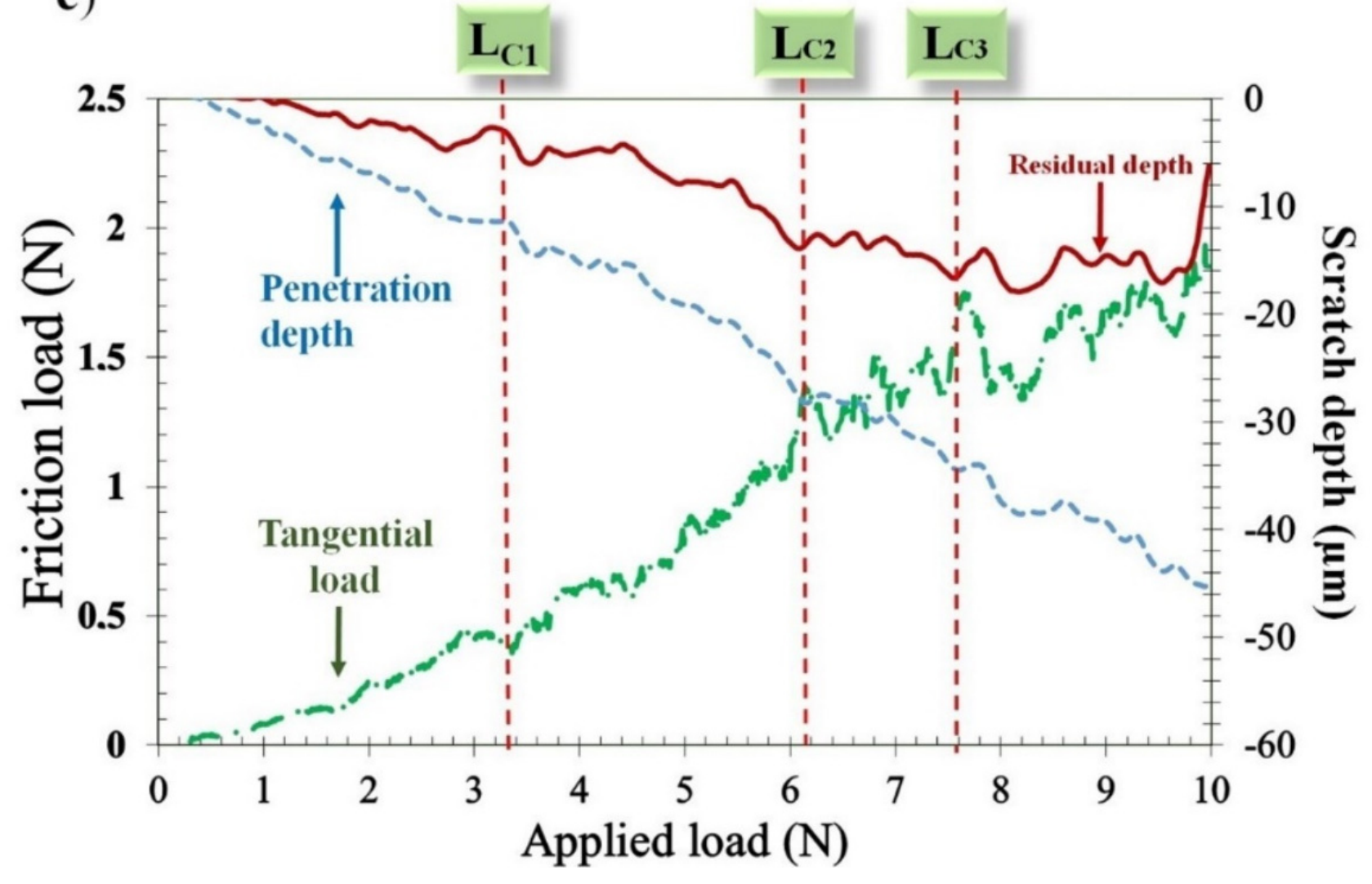

Figure 4. Progressive scratch test on an FEP coating. (a) SEM micrographs of scratch tracks. Magnified photo at (b) $\mathrm{L}_{\mathrm{c} 1}$, (c) $\mathrm{L}_{\mathrm{c} 2}$, and (d) $\mathrm{L}_{\mathrm{c} 3}$. (e) Tangential load, penetration, and residual depths as functions of the applied load.

\subsection{Friction and Wear Resistance}

Multi-pass sliding scratch testing was performed on the FEP coatings to evaluate the friction behavior and wear resistance. The SEM micrographs and EDS analyses of the multi-pass scratch test of FEP coatings at different applied loads are presented in Figure 5. 
The wear tracks obtained under 100 sliding cycles at constant loads of $0.3,1,2$, and $3 \mathrm{~N}$ were examined using SEM. The applied load was lower than the cohesive failure load $\left(\mathrm{L}_{\mathrm{c} 1}\right)$ of the coatings.

a)

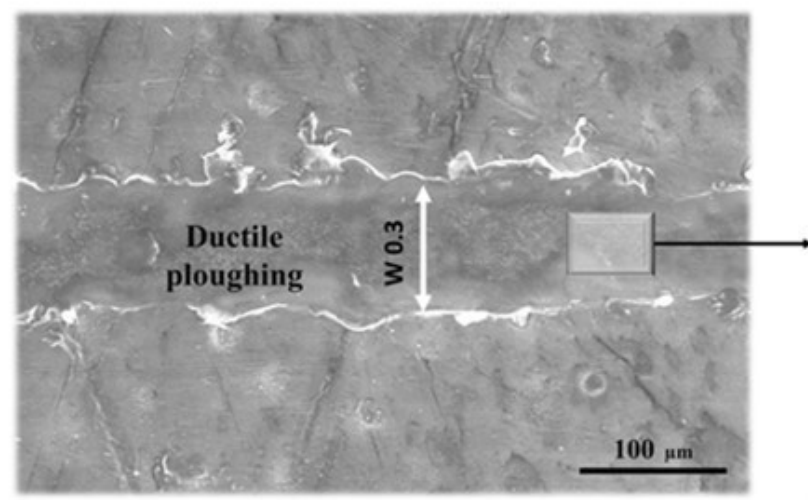

b)

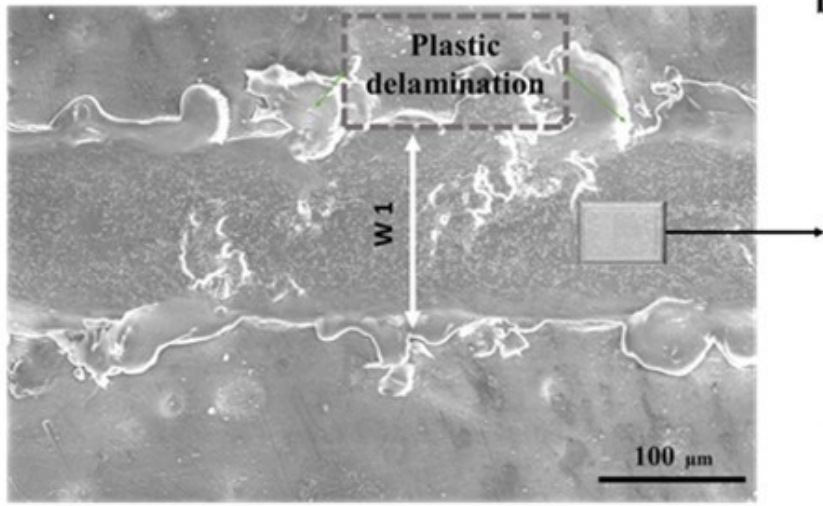

c)

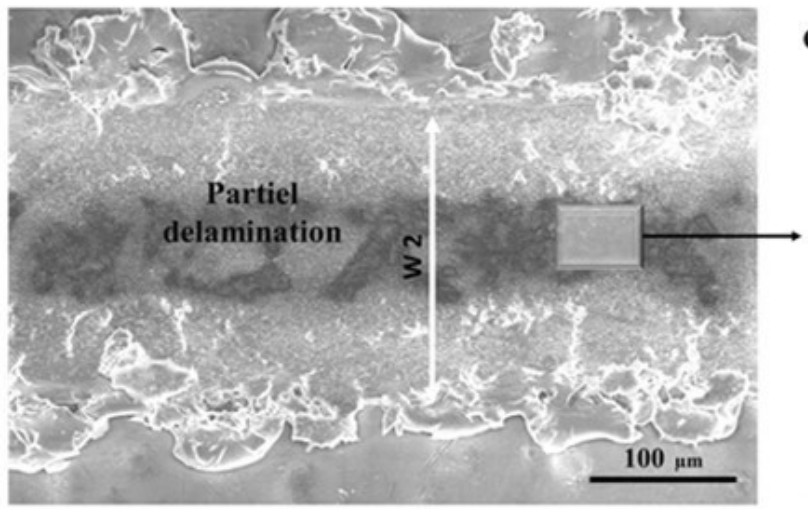

d)

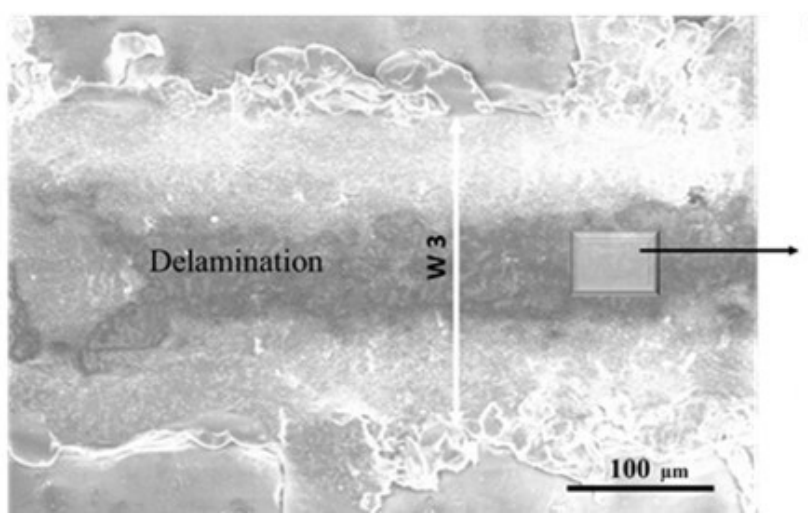

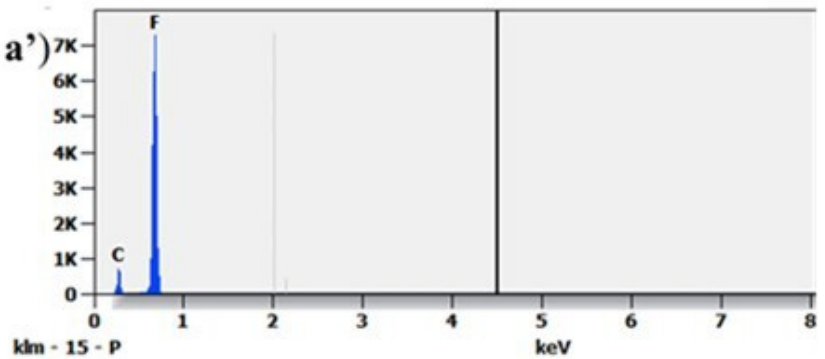

b')

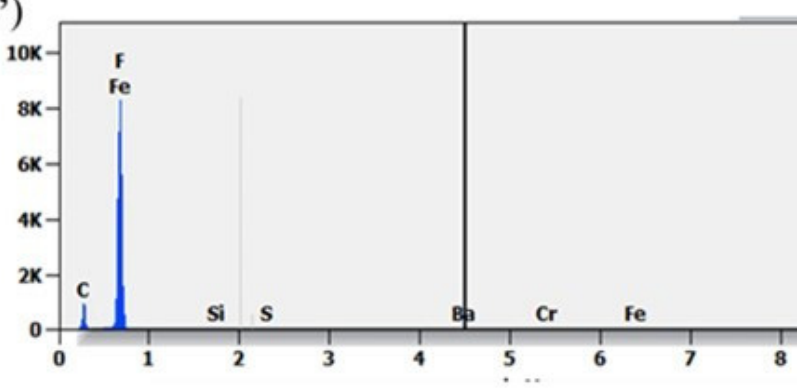

c')

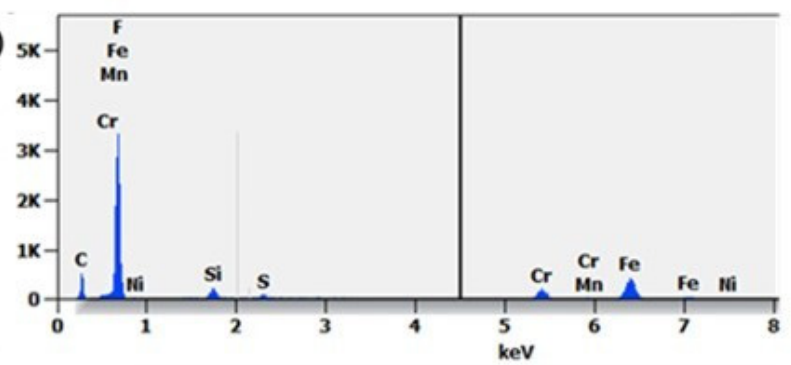

d')

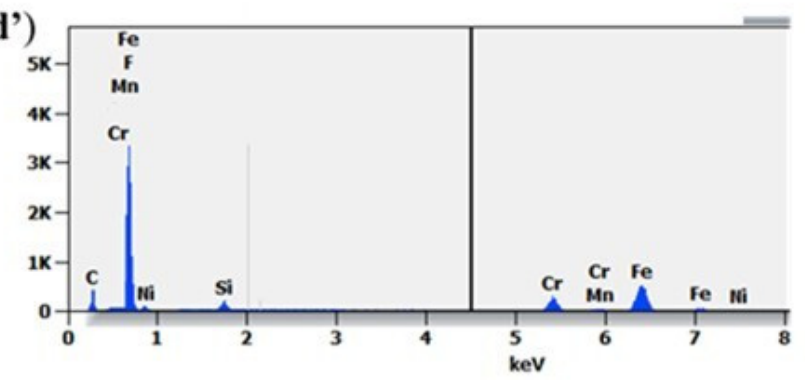

Figure 5. SEM micrographs and corresponding EDS analyses of 100-pass scratch tracks at (a) $0.3 \mathrm{~N}$, (b) $1 \mathrm{~N},(\mathbf{c}) 2 \mathrm{~N}$, and (d) $3 \mathrm{~N}$. 
Figure 5 illustrates the SEM images of the scratch tracks at various applied loads $(0.3$, 1,2 , and 3 N). As demonstrated in Figure 5, after a 100-pass scratching, the width of the scratch tracks increased considerably as the loading was raised. At $0.3 \mathrm{~N}$, the SEM results revealed plastic deformation located at the edge and a ductile ploughing in the center of the track. At $1 \mathrm{~N}$, an increased plastic deformation was noticed at the edge and in the center of the tracks, but the film still adhered to its substrate, and only cohesive failure occurred. However, at higher loads ( 2 and $3 \mathrm{~N}$ ), an extensive plastic deformation occurred, leading to a chipping phenomenon. At this stage, the FEP coating demonstrated delamination, which was an indication of adhesive wear.

This result was proved by EDS analysis of the wear tracks, as shown in Figure 5 and Table 2. For the applied load of $0.3 \mathrm{~N}$, the chemical composition present in the wear track (Figure 5a') was the same as that obtained in the film (see Figure 2b). Then, at $1 \mathrm{~N}$ (Figure $5 b^{\prime}$ ), trace amounts of iron were noticed, but nevertheless, after 100 passes and at a load of $1 \mathrm{~N}$, the film behavior remained cohesive.

Table 2. Chemical composition of the film after and before wear tracks.

\begin{tabular}{lccccccccc}
\hline & \multicolumn{7}{c}{ Chemical Composition (wt) } \\
\cline { 2 - 10 } & C & F & Si & S & Mn & Cr & Fe & Ni \\
\hline Track of 0.3 N & 21.10 & 78.90 & & & & 0.40 & 1.75 & \\
Track of 1 N & 20.09 & 77.62 & 0.125 & 0.015 & & 0.38 & 4.90 & 14.3 & 1.59 \\
Track of 2 N & 14.45 & 63.56 & 0.80 & 0.020 & 0.46 & 6.86 & 24.17 & 2.45 \\
Track of 3 N & 10.58 & 54.6 & 0.86 & 0.02 & &
\end{tabular}

However, at higher loads ( 2 and 3 N) (cf. Figure $\left.5 c, d^{\prime}\right)$, the EDS analysis showed the appearance of the substrate elements $\mathrm{C}$ and $\mathrm{Fe}$ in the wear tracks during sliding (see Table 2). The elevated loading level and the high mechanical properties led to excessive Hertzian stresses, which promoted coating wear in the middle of the wear track [32].

The results of the wear tests in terms of friction coefficient and wear volume are illustrated in Figure 6. The evolution of the coefficients of friction of the coatings is presented as a function of the number of cycles for various applied loads in Figure 6a and after 100 cycles at various applied loads and velocities in Figure $6 b$.

The friction coefficient (COF) was recorded for 100 passes at each load. It can be noticed that the increase in the applied load led to a higher average value of the friction coefficient. At the lowest loads $(0.3$ and $1 \mathrm{~N})$, the film had an exceedingly low friction coefficient that did not exceed 0.13 at 100 passes.

At higher applied loads ( $2 \mathrm{~N}$ and $3 \mathrm{~N})$, the COF was, respectively, 0.18 and 0.24 at 100 passes. The increase in COF value for high applied loads was explained by the appearance of substrate after partial delamination of the FEP coating. The low friction coefficient reflects the high friction resistance of this coating. Such results were like those found by Nemati et al. [33]. Authors found that coating of the fluoropolymer PTFE on stainless steel was effective in lowering the COF from 1.2 to 0.16 . The low and stable behavior of the COF was due to the synergistic lubrication effects of PTFE [34].

For each applied load and sliding velocity, the wear volume (V) and dissipated energy (E) were measured. The evolution of the wear volume was plotted versus the applied load for each sliding velocity, as shown in Figure 6c. Raising the applied load led to a significant increase in wear volume and dissipated energy regardless of the sliding velocity. This tendency was confirmed by the analysis of micrographs and the chemical composition of wear tracks, as previously observed. Concerning the velocity effect, the wear volume increased as the sliding velocity increased from 50 to $100 \mathrm{~mm} \mathrm{~min}^{-1}$.

The evolution of the wear volume (V) was plotted versus the dissipated energy (E) (see Figure 6d). Each point on this plot represents an experiment carried out at a given load $(0.3,1 \mathrm{~N}, 2 \mathrm{~N}$, and $3 \mathrm{~N})$ and for a given sliding speed (10, 50, and $\left.100 \mathrm{~mm} \mathrm{~min}^{-1}\right)$. The obtained graph reports a linear relation, and the slope of (E) vs. (V) is defined as the wear 
coefficient. Such an approach has already been successfully used in other works [26], and herein, the wear coefficient was equal to $3.12 \times 10^{-4} \mathrm{~mm}^{3} \mathrm{~N} \mathrm{~m}^{-1}$. This was of the same order of magnitude as that reported in other studies using both PFA and PTFE with wear rates corresponding to $\sim 10^{-4} \mathrm{~mm}^{3} \mathrm{~N} \mathrm{~m}^{-1}$ [35].

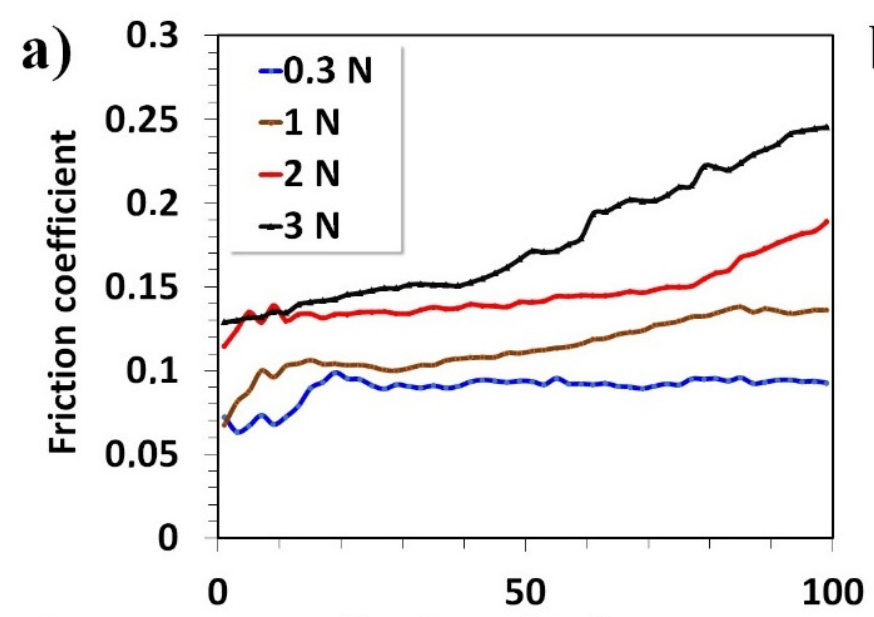

c)
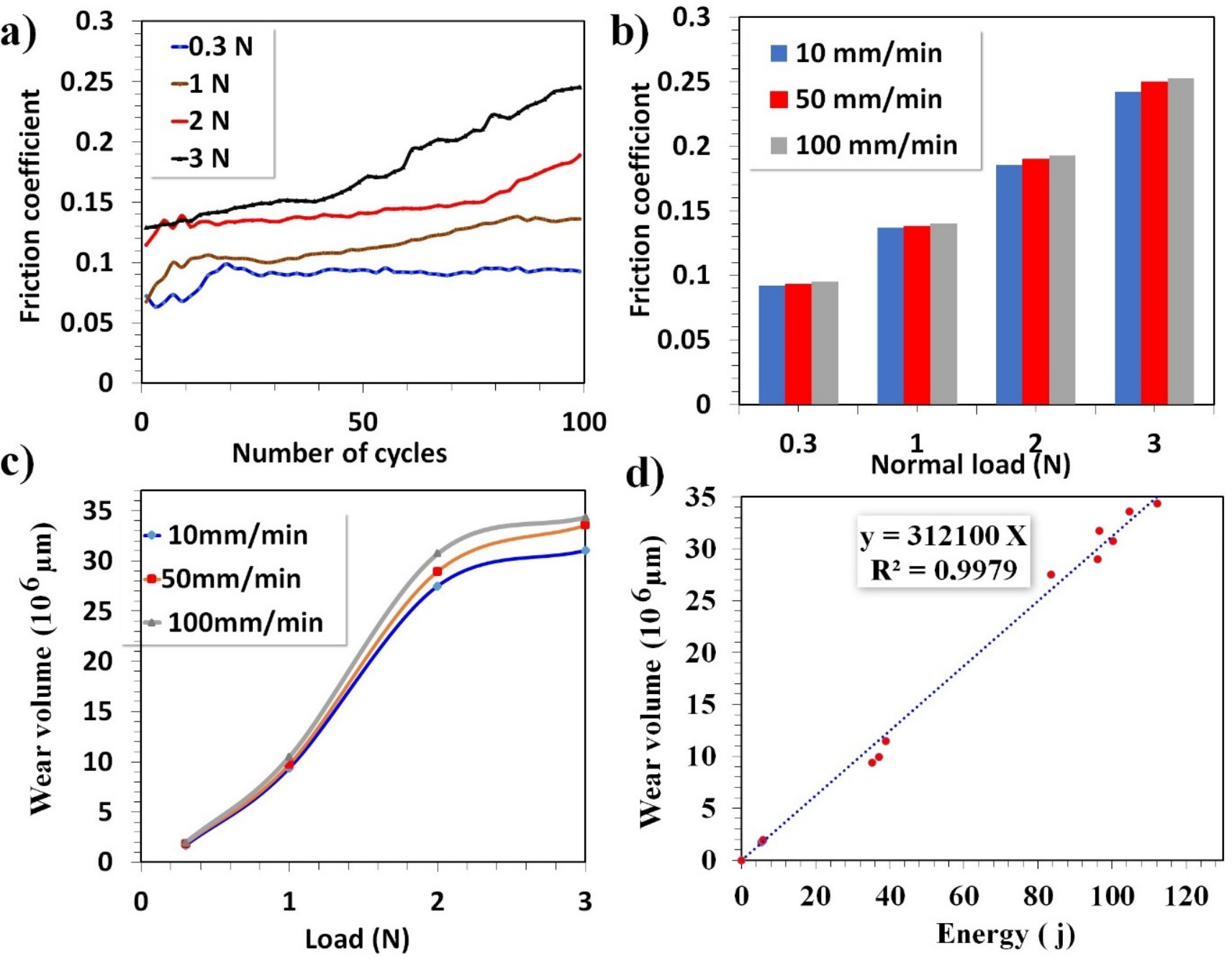

Figure 6. (a) COF plot of FEP coatings versus the number of cycles for $0.3,1,2$, and $3 \mathrm{~N}$ at $50 \mathrm{~mm} \mathrm{~min}^{-1}$, (b) COF bar graph and (c) wear volume versus load after 100 passes at various velocities, and (d) wear volume as a function of the dissipated energy.

\subsection{Corrosion Resistance}

The cathodic and anodic polarization curves recorded for the SS304 and FEP coating at $\mathrm{t}=1 \mathrm{~h}$ and after 60 days of immersion in $3.5 \mathrm{wt} \% \mathrm{NaCl}$ solution are shown in Figure 7, and the specific data (Table 3) were obtained by Tafel fitting of these curves. The corrosion resistance of the coating can be described in detail by the electrodynamic polarization curve, and the lower polarization current indicated a superior corrosion resistance [36].

The extrapolation of the polarization curves was carried out to determine $\mathrm{I}_{\text {corr }}$ and $\mathrm{E}_{\text {corr }}$ (Figure 7, Table 3). As seen in Figure 7, the corrosion current density of SS304 decreased from $33 \times 10^{-4}$ to $1.58 \times 10^{-4} \mathrm{\mu A} / \mathrm{cm}^{2}$ with the coating deposition. In addition, the corrosion potential was raised from $-450 \mathrm{mV}$ to $-240 \mathrm{mV}$. The enhancement of the SS304 corrosion resistance is associated with the physical-chemical characteristics of the FEP resins $[10,37-40]$. 


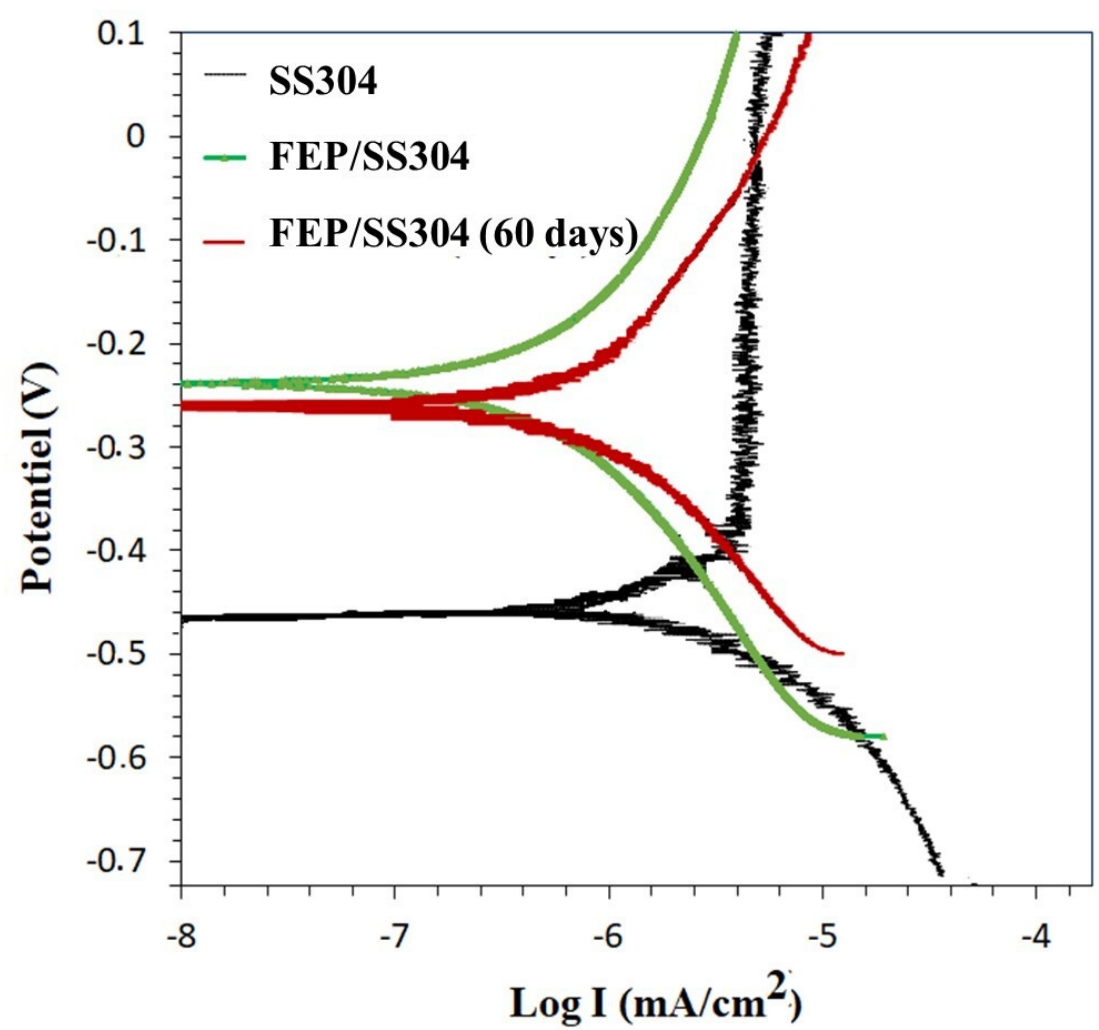

Figure 7. Polarization curve of SS304 and FEP coatings in $3.5 \% \mathrm{NaCl}$ for $1 \mathrm{~h}$ and for 60 days.

Table 3. Potentiodynamic polarization data of SS304 and FEP coating.

\begin{tabular}{ccccc}
\hline Immersion Time & Samples & $\mathbf{E}_{\text {corr }}(\mathbf{m V})$ & $\begin{array}{c}\mathbf{I}_{\text {corr }} \\
\left(\boldsymbol{\mu} \mathbf{A} / \mathbf{c m}^{-2}\right)\end{array}$ & Inhibition Efficiency (\%) \\
\hline \multirow{2}{*}{$1 \mathrm{~h}$} & SS304 & -450 & $33.1 \times 10^{-4}$ & - \\
\cline { 2 - 5 } & $\mathrm{FEP} / \mathrm{SS} 304$ & -240 & $1.58 \times 10^{-4}$ & 95.22 \\
\hline 60 days & $\mathrm{FEP} / \mathrm{SS} 304$ & -264 & $2.51 \times 10^{-4}$ & 92.4 \\
\hline
\end{tabular}

To further demonstrate the long-term anti-corrosion performance of the FEP coatings, polarization measurements were performed after immersing them in a $3.5 \mathrm{wt} \% \mathrm{NaCl}$ corrosive environment for 60 days. According to Table 3 and Figure 7, a very small negative shift in $\mathrm{E}_{\text {corr }}$ and few positive shifts of $\mathrm{I}_{\text {corr }}$ were observed. This indicated that the anticorrosion performance of the coatings was consistent after the immersion test. Moreover, the inhibition efficiency of the coatings to SS304 remained remarkable after the 60-day immersion test. The FEP coatings could further extend their protective effect by inhibiting the penetration of the corrosion medium into the stainless-steel substrate when in an aggressive and humid environment. Thus, FEP protected the product from any kind of chemical corrosion.

\section{Conclusions}

In this work, a protective FEP coating was deposited on a stainless-steel substrate using the air spray process and then cured to obtain a compact and uniform film. The mechanical, adhesion, tribological, and corrosion performance of FEP coatings were investigated by nanoindentation, scratch test, SEM, and cyclic voltammetry. The following conclusions were drawn from the experimental results. The FEP coatings exhibited a dense, poreless, and homogeneous structure with a pseudohexagonal lattice crystalline structure. They showed good mechanicals properties, hardness, and Young's modulus and good scratch 
resistance to adhesive and cohesive failure, with a high adhesion to SS304. During the multi-pass scratch test of the FEP coating, both the wear volume and the dissipated energy increased when the normal applied load and sliding velocity were raised. It was also deduced that the coating exhibited a ductile behavior. After the wear tests, the wear on the FEP coatings with the increase of the applied load passed from cohesive wear to adhesive wear. The multi-pass scratch provided an easy and quick approach to study FEP wear resistance. The friction coefficient of the FEP coating did not exceed 0.13 , and the wear coefficient was around $3.12 \times 10^{-4} \mathrm{~mm}^{3} \mathrm{~N} \mathrm{~m}^{-1}$. The FEP coating enhanced the corrosion resistance of SS304 and provided a significant protection during 60 days of immersion in a $\mathrm{NaCl}$ solution.

Author Contributions: Conceptualization, N.B., K.L. and A.M.; methodology, N.B. and K.K.; validation, K.L. and A.M.; formal analysis, N.B. and K.K.; investigation, N.B. data curation, N.B. and K.K.; writing—original draft preparation, N.B.; writing—review and editing, K.L.; supervision, K.L.; project administration, K.L.; funding acquisition, K.L. and A.M. All authors have read and agreed to the published version of the manuscript.

Funding: This research received no external funding.

Institutional Review Board Statement: Not applicable.

Informed Consent Statement: Not applicable.

Data Availability Statement: Not applicable.

Acknowledgments: This work was carried out under a partnership agreement with the RIET industry Revetement Industriel EURO-Tunisien, Zaghouan, Tunisia. The authors acknowledge their manager Ramzi Hachicha for his assistance.

Conflicts of Interest: The authors declare no conflict of interest.

\section{References}

1. Boillot, P.; Peultier, J. Use of Stainless Steels in the Industry: Recent and Future Developments. Procedia Eng. 2014, 83, 309-321. [CrossRef]

2. Bodur, T.; Cagri-Mehmetoglu, A. Removal of Listeria monocytogenes, Staphylococcus aureus and Escherichia coli O157:H7 biofilms on stainless steel using scallop shell powder. Food Control. 2012, 25, 1-9. [CrossRef]

3. Ismaïl, R.; Aviat, F.; Michel, V.; Le Bayon, I.; Gay-Perret, P.; Kutnik, M.; Fédérighi, M. Methods for Recovering Microorganisms from Solid Surfaces Used in the Food Industry: A Review of the Literature. Int. J. Environ. Res. Public Health 2013, 10, 6169-6183. [CrossRef]

4. Cooper, I.; Tice, P. Food contact coatings-European legislation and future predictions. Surf. Coat. Int. Part B Coat. Trans. 2001, 84, 105-112. [CrossRef]

5. Berman, D.; Erdemir, A.; Sumant, A.V. Reduced wear and friction enabled by graphene layers on sliding steel surfaces in dry nitrogen. Carbon 2013, 59, 167-175. [CrossRef]

6. Zhang, H.; Zhao, Y.; Jiang, Z. Effects of temperature on the corrosion behavior of $13 \mathrm{Cr}$ martensitic stainless steel during exposure to $\mathrm{CO}_{2}$ and $\mathrm{Cl}^{-}$environment. Mater. Lett. 2005, 59, 3370-3374. [CrossRef]

7. Ziemniak, S.; Hanson, M. Corrosion behavior of 304 stainless steel in high temperature, hydrogenated water. Corros. Sci. 2002, 44, 2209-2230. [CrossRef]

8. Peter, I.; Rosso, M.; Gobber, F.S. Study of protective coatings for aluminum die casting molds. Appl. Surf. Sci. 2015, 358, 563-571. [CrossRef]

9. Rodríguez-Alabanda, Ó.; Romero, P.E.; Soriano, C.; Sevilla, L.; Guerrero-Vaca, G. Study on the Main Influencing Factors in the Removal Process of Non-Stick Fluoropolymer Coatings Using Nd:YAG Laser. Polymers 2019, 11, 123. [CrossRef] [PubMed]

10. Barhoumi, N.; Dhiflaoui, H.; Kaouther, K.; Ben Rhouma, A.; Hamdi, F. Study of Wear and Corrosion Performance of Fluoropolymer PFA Electrostatically Deposited on 304 Steel. In Advances in Mechanical Engineering and Mechanics II; Lecture Notes in Mechanical Engineering; Bouraoui, T., Ed.; Springer: Cham, Switzerland, 2021; pp. 103-110. [CrossRef]

11. Primc, G. Recent Advances in Surface Activation of Polytetrafluoroethylene (PTFE) by Gaseous Plasma Treatments. Polymers 2020, 12, 2295. [CrossRef] [PubMed]

12. Ohkubo, Y.; Okazaki, Y.; Shibahara, M.; Nishino, M.; Seto, Y.; Endo, K.; Yamamura, K. Effects of He and Ar Heat-Assisted Plasma Treatments on the Adhesion Properties of Polytetrafluoroethylene (PTFE). Polymers 2021, 13, 4266. [CrossRef] [PubMed]

13. Shim, E.; Jang, J.-P.; Moon, J.-J.; Kim, Y. Improvement of Polytetrafluoroethylene Membrane High-Efficiency Particulate Air Filter Performance with Melt-Blown Media. Polymers 2021, 13, 4067. [CrossRef] [PubMed] 
14. Ebnesajjad, S.; Khaladkar, P.R. Fluoropolymer Applications in the Chemical Processing Industries: The Definitive User's Guide and Handbook; Elsevier Science: Amsterdam, The Netherlands, 2017.

15. Guerrero-Vaca, G.; Carrizo-Tejero, D.; Rodríguez-Alabanda, Ó; Romero, P.E.; Molero, E. Experimental Study for the Stripping of PTFE Coatings on Al-Mg Substrates Using Dry Abrasive Materials. Materials 2020, 13, 799. [CrossRef]

16. Olifirov, L.K.; Stepashkin, A.A.; Sherif, G.; Tcherdyntsev, V.V. Tribological, Mechanical and Thermal Properties of Fluorinated Ethylene Propylene Filled with Al-Cu-Cr Quasicrystals, Polytetrafluoroethylene, Synthetic Graphite and Carbon Black. Polymers 2021, 13, 781. [CrossRef]

17. Cardoso, V.F.; Correia, D.M.; Ribeiro, C.; Fernandes, M.M.; Lanceros-Méndez, S. Fluorinated Polymers as Smart Materials for Advanced Biomedical Applications. Polymers 2018, 10, 161. [CrossRef]

18. Teng, H. Overview of the Development of the Fluoropolymer Industry. Appl. Sci. 2012, 2, 496-512. [CrossRef]

19. Chen, B.; Wang, J.; Yan, F. Friction and Wear Behaviors of Several Polymers Sliding Against GCr15 and 316 Steel Under the Lubrication of Sea Water. Tribol. Lett. 2011, 42, 17-25. [CrossRef]

20. Akram, W.; Rafique, A.F.; Maqsood, N.; Khan, A.; Badshah, S.; Khan, R.U. Khan Characterization of PTFE Film on 316L Stainless Steel Deposited through Spin Coating and Its Anticorrosion Performance in Multi Acidic Mediums. Materials 2020, 13, 388. [CrossRef]

21. Chen, X.; Yuan, J.; Huang, J.; Ren, K.; Liu, Y.; Lu, S.; Li, H. Large-scale fabrication of superhydrophobic polyurethane/nano- $\mathrm{Al}_{2} \mathrm{O}_{3}$ coatings by suspension flame spraying for anti-corrosion applications. Appl. Surf. Sci. 2014, 311, 864-869. [CrossRef]

22. Ferreira, E.S.; Giacomelli, C.; Spinelli, A. Evaluation of the inhibitor effect of l-ascorbic acid on the corrosion of mild steel. Mater. Chem. Phys. 2004, 83, 129-134. [CrossRef]

23. Xu, Y.; Qin, J.; Shen, J.; Guo, S.; Lamnawar, K. Scratch behavior and mechanical properties of alternating multi-layered PMMA/PC materials. Wear 2021, 486-487, 204069. [CrossRef]

24. Panin, S.V.; Luo, J.; Buslovich, D.G.; Alexenko, V.O.; Kornienko, L.A.; Bochkareva, S.A.; Byakov, A.V. Experimental-FEM Study on Effect of Tribological Load Conditions on Wear Resistance of Three-Component High-Strength Solid-Lubricant PI-Based Composites. Polymers 2021, 13, 2837. [CrossRef]

25. Moon, S.W.; Seo, J.; Seo, J.-H.; Choi, B.-H. Scratch Properties of Clear Coat for Automotive Coating Comprising Molecular Necklace Crosslinkers with Silane Functional Groups for Various Environmental Factors. Polymers 2021, 13, 3933. [CrossRef] [PubMed]

26. Khlifi, K.; Dhiflaoui, H.; Ben Aissa, C.; Barhoumi, N.; Larbi, A.B.C. Friction and Wear Behavior of a Physical Vapor Deposition Coating Studied Using a Micro-Scratch Technique. J. Eng. Mater. Technol. 2022, 144, 1-26. [CrossRef]

27. Oliver, W.C.; Pharr, G.M. An improved technique for determining hardness and elastic modulus using load and displacement sensing indentation experiments. J. Mater. Res. 1992, 7, 1564-1583. [CrossRef]

28. Mendibide, C.; Fontaine, J.; Steyer, P.; Esnouf, C. Dry Sliding Wear Model of Nanometer Scale Multilayered TiN/CrN PVD Hard Coatings. Tribol. Lett. 2004, 17, 779-789. [CrossRef]

29. Panda, P.K.; Yang, J.-M.; Chang, Y.-H. Water-induced shape memory behavior of poly (vinyl alcohol) and p-coumaric acidmodified water-soluble chitosan blended membrane. Carbohydr. Polym. 2021, 257, 117633. [CrossRef]

30. Tcherdyntsev, V.V.; Olifirov, L.K.; Kaloshkin, S.D.; Zadorozhnyy, M.Y.; Danilov, V.D. Thermal and mechanical properties of fluorinated ethylene propylene and polyphenylene sulfide-based composites obtained by high-energy ball milling. J. Mater. Sci. 2018, 53, 13701-13712. [CrossRef]

31. Sulen, W.L.; Ravi, K.; Bernard, C.; Ichikawa, Y.; Ogawa, K. Deposition Mechanism Analysis of Cold-Sprayed Fluoropolymer Coatings and Its Wettability Evaluation. J. Therm. Spray Technol. 2020, 29, 1643-1659. [CrossRef]

32. Ordoñez, M.F.C.; Paruma, J.S.R.; Osorio, F.S.; Farias, M.C.M. The Effect of Counterpart Material on the Sliding Wear of TiAlN Coatings Deposited by Reactive Cathodic Pulverization. Sci. Cum Ind. 2015, 3, 59-66. [CrossRef]

33. Nemati, N.; Emamy, M.; Yau, S.; Kim, J.-K.; Kim, D.-E. High temperature friction and wear properties of graphene oxide/polytetrafluoroethylene composite coatings deposited on stainless steel. RSC Adv. 2016, 6, 5977-5987. [CrossRef]

34. Wang, H.; Sun, A.; Qi, X.; Dong, Y.; Fan, B. Experimental and Analytical Investigations on Tribological Properties of PTFE/AP Composites. Polymers 2021, 13, 4295. [CrossRef]

35. Sidebottom, M.A.; Pitenis, A.A.; Junk, C.P.; Kasprzak, D.J.; Blackman, G.S.; Burch, H.E.; Harris, K.L.; Sawyer, W.G.; Krick, B. Ultralow wear Perfluoroalkoxy (PFA) and alumina composites. Wear 2016, 362-363, 179-185. [CrossRef]

36. Kumar, A.; Ghosh, P.K.; Yadav, K.L.; Kumar, K. Thermo-mechanical and anti-corrosive properties of MWCNT/epoxy nanocomposite fabricated by innovative dispersion technique. Compos. Part B Eng. 2017, 113, 291-299. [CrossRef]

37. Husain, E.; Nazeer, A.A.; Alsarraf, J.; Al-Awadi, K.; Murad, M.; Al-Naqi, A.; Shekeban, A. Corrosion behavior of AISI 316 stainless steel coated with modified fluoropolymer in marine condition. J. Coat. Technol. Res. 2018, 15, 945-955. [CrossRef]

38. Delimi, A.; Galopin, E.; Coffinier, Y.; Pisarek, M.; Boukherroub, R.; Talhi, B.; Szunerits, S. Investigation of the cor-rosion behavior of carbon steel coated with fluoropolymer thin films. Surf. Coat. Technol. 2011, 205, 4011-4017. [CrossRef]

39. Liang, J.; Azhar, U.; Men, P.; Chen, J.; Liu, Y.; He, J.; Geng, B. Fluoropolymer/SiO 2 encapsulated aluminum pigments for enhanced corrosion protection. Appl. Surf. Sci. 2019, 487, 1000-1007. [CrossRef]

40. Leivo, E.; Wilenius, T.; Kinos, T.; Vuoristo, P.; Mäntylä, T. Properties of thermally sprayed fluoropolymer PVDF, ECTFE, PFA and FEP coatings. Prog. Org. Coat. 2004, 49, 69-73. [CrossRef] 